\title{
Understanding Wrist Mechanics: A Long and Winding Road*
}

\author{
Marc Garcia-Elias, MD, $\mathrm{PhD}^{1}$ \\ ${ }^{1}$ The Institut Kaplan, Hand and Upper Extremity Surgery, Barcelona, \\ Spain
}

J Wrist Surg 2013;2:5-12.
Address for correspondence Dr. Marc Garcia-Elias, MD, PhD, Institut Kaplan, Passeig de la Bonanova, 9, 2on 2a, 08022 Barcelona, Spain (e-mail: garciaelias@institut-kaplan.com).
The title of this Clinical Perspective has been borrowed from a song by Paul McCartney, a song that emphasizes the difficulties of reaching one's dreams. If I choose that title, it is because it describes quite well my own experience as wrist investigator. Truly, my struggling to understand carpal mechanics has been like a long and winding road; an exciting road, indeed, but one not devoid of unexpected curves and misleading signposts: an endless road for a hopeless wrist enthusiast (-Fig. 1).

I got "infected" by the carpal virus in the early 1980s, when I had the chance of attending a seminar organized by Carlos Irisarri in Madrid about wrist injuries. The program was unusual. I was expecting to learn some tips about the management of scaphoid fractures, but I found myself diving in a pool of unknown terminology: carpal misalignment, segmental instability, rotary subluxation. What a tsunami of thought-provoking concepts! What a challenge for a poorly trained orthopedic surgeon from the suburbs of Barcelona like me! I'll never forget the thrill of questioning Ron Linscheid and Julio Taleisnik that day, Of course, I hardly understood their kind answers: I was too inexperienced to comprehend that new world. Later that week I read the seminal papers of Drs. Linscheid, Dobyns, and Taleisnik about carpal instability, ${ }^{1,2}$ but I could not get the message. If I wanted to swim in that pool, I first needed to learn the basics of swimming. So I went back to the Anatomy department and started from scratch.

The history of how we all got to know the wrist is a long one. Vesalius, in the 16th century, had already made precise drawings of the carpal bones. ${ }^{3}$ Their function, however, was pretty much ignored for centuries. See, for instance, the only two lines that Sir Charles Bell wrote in 1833 about the wrist in his classical Bridgewater treatise. "The carpal bones," he said, "are so closely connected that they form a sort of ball which moves on the end of the radius." Surprisingly, only 8 years later, a 143-page book about the functional anatomy of the wrist was published by Gustav Günther from Hamburg in Germany. ${ }^{5}$ Not only had he spent hours and hours in the laboratory dissecting and observing wrist specimens, but he had measured radii of curvatures at both radiocarpal and midcarpal levels at a time when X-rays were not available. As far as I know, this recently rediscovered book was the first ever published about the wrist.

After Günther's publication, the carpus became a hot issue to explore, and luminaries such as Wilhelm Henke ${ }^{6}$ and Friedrich Henle ${ }^{7}$ added new discoveries about intracarpal motion. Henke ${ }^{6}$ was the first to suggest differential mobility between the proximal and distal rows, while Henle ${ }^{7}$ came out with the first description of the two major axes of wrist motion. The discovery of X-rays triggered an explosion of new data in just few years. Bryce ${ }^{8}$ was the first to recognize that there is also differential motion between scaphoid and lunate. Corson $^{9}$ noticed how important the so-called dart-throwing rotation is in most daily activities. Fick ${ }^{10}$ realized that the two axes of wrist rotation were not orthogonal, intersecting on the same plane, but oblique and biplanar. Destot ${ }^{11}$ was the first to describe scapholunate dissociation. Yes, those were the early golden years after which the wrist was no longer a block of fixed bones but a fascinating mechanism of small joints, each with its own motion. Unfortunately, the First World War put an end to all of that, and the carpus had to wait 50 more years until it again drew some attention ... but this is not the story I wanted to write about. I am not a historian.

The story I promised to report on is my own experience: the story of my journey to understand carpal stability. I could as well have told you about my struggles to understand carpal motion, but the message would have been the same: Knowledge does not progress if one is not willing to reconsider one's viewpoints when new evidence suggests them to be untrue.

In the early 1980s, I read everything about the subject, but my level of dissatisfaction was still high. I wanted certainties, not speculations. Infected as I was by the carpal virus, I needed to see things for myself. Cooney and Chao ${ }^{12}$ had, not long before, demonstrated that the amount of force transmitted across the carpus was much larger than previously thought. Indeed, the wrist resists substantial amounts of load, but how can this little joint resist that without yielding? That was one of the questions I was obsessed with. I spent 5 years in the anatomy laboratory of the
Copyright (c) 2013 by Thieme Medical Publishers, Inc., 333 Seventh Avenue, New York, NY 10001, USA. Tel: +1(212) 584-4662.
DOI http://dx.doi.org/ $10.1055 / \mathrm{s}-0032-1333429$. ISSN 2163-3916. 


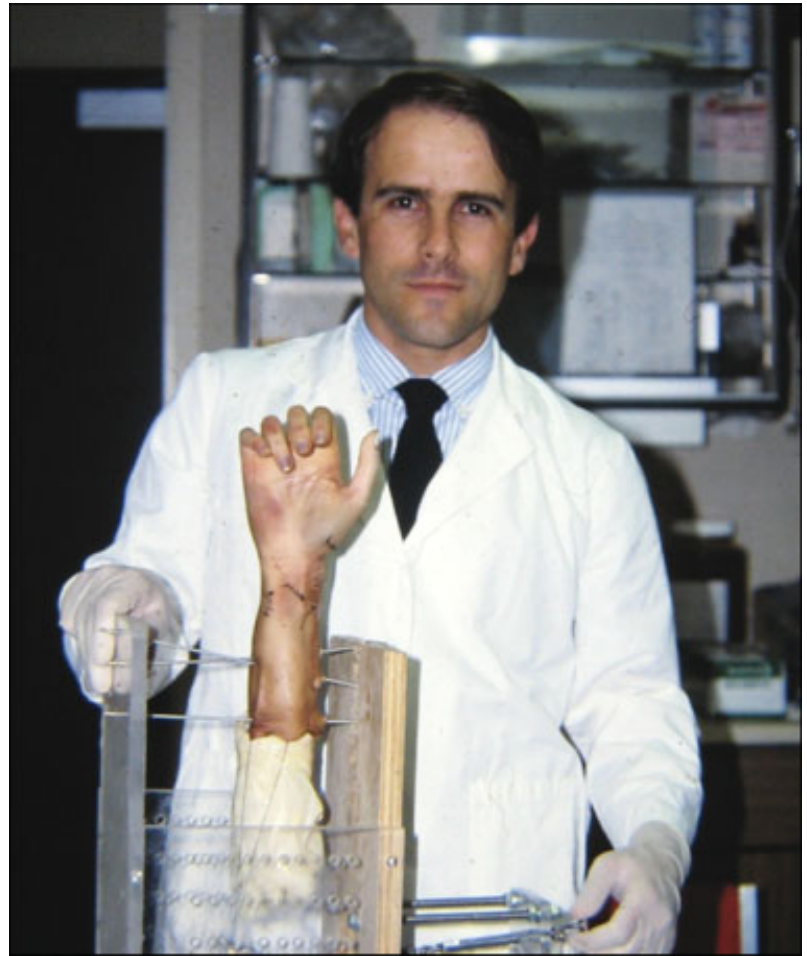

Fig. 1 Preparing a specimen to investigate the effects of partial carpal fusions in the kinematics of the wrist. Biomechanics Laboratory, Mayo Clinic, Rochester MN. October 1987.

Universitat Autònoma de Barcelona, and I earned my PhD studying ulnar-side carpal injuries. I struggled to find a mechanical model that could explain carpal stability, and I found it. The scaphoid had to be the key to unveil that riddle. Of course, as stated in Ecclesiastes, "there is nothing new under the sun"-most of my thoughts had been thought already. My long and winding journey had just started. My first stop would be the scaphoid.

\section{The Scaphoid: The Key to Carpal Stability}

Geoffrey Fisk, ${ }^{13}$ in his Hunterian lecture delivered at the Royal College of Surgeons in 1968 (45 years ago now) had already stated that the wrist is a link system with a tendency to collapse into a zigzag pattern, which he called the concertina effect. According to that theory, the scaphoid was the key element preventing the concertina effect. Certainly, when the carpus is axially loaded, the lunate tends to rotate into extension while the capitate translates dorsally. That's the concertina effect. However, if we have an intercalated scaphoid with proximal and distal links to the dorsum of the lunate and to the palmar edge of the capitate, there is an obvious sense of elastic stability that eliminates the risk of carpal collapse (-Fig. 2). Unquestionably, the scaphoid as a bridge between the two carpal rows was a good model to explain stability.

That idea was not entirely new, however. It was derived from the teachings of Professor Constantine Lambrinudi to his fellows Gilford and Bolton, who published a quite similar theory several years before. ${ }^{14}$ Later on, Linscheid and asso-

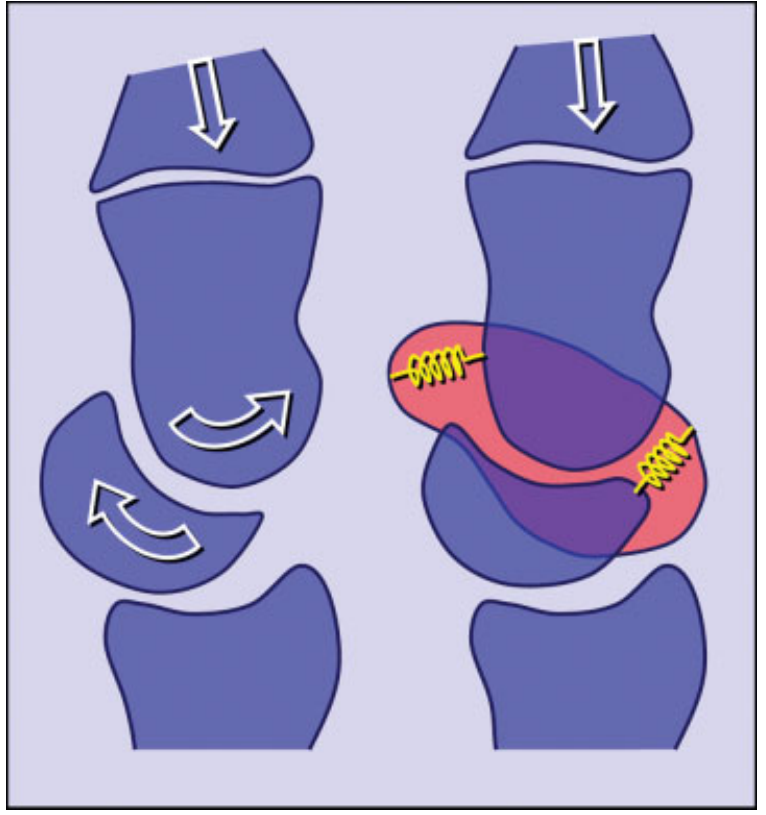

Fig. 2 According to Lambrinudi, ${ }^{14}$ the scaphoid is the key element in preventing the "concertina" effect (white arrows), as long as the palmar scaphocapitate and dorsal scapholunate links (yellow springs) are intact.

ciates, ${ }^{1}$ with their "slider-crank" mechanical model, further emphasized the importance of the scaphoid for the wrist to be both mobile and stable. I must confess that, when I carefully read those articles, I thought that I had finally understood the carpus.

But of course that explanation was not devoid of drawbacks. In a way, that theory appeared to indicate that any alteration of the carpal alignment was the result of intracarpal pathology. Yet, as demonstrated by Professor Allieu ${ }^{15}$ at Montpellier, France, carpal malalignment is not always the result of intracarpal pathology; it may occasionally be an adaptation to something wrong outside the carpus. Needless to say, carpal malalignment and carpal instability are not equivalent terms. A dorsally tilted radial fracture, for instance, may exhibit malalignment as an adaptive phenomenon, which may disappear when the fracture is reduced. In other words, the theory according to which the scaphoid was the key to normal carpal alignment was not valid any more. My road to understanding carpal stability would not be a straight one.

\section{The Scapholunate Stabilization Model}

It was in the early 1980s that I got fascinated by the new concepts defended by Professors Landsmeer ${ }^{16}$ at Leiden in The Netherlands. Not long before, one of his associates Professor, John Kauer, ${ }^{17}$ had moved to the University of Nijmegen, also in The Netherlands, and became full professor of anatomy. These two gentlemen had gone a step ahead by emphasizing the role of the scapholunate ligaments in the stabilization of the wrist. The lunate, they said, is wedgeshaped, being narrower dorsally than palmarly, and therefore, 


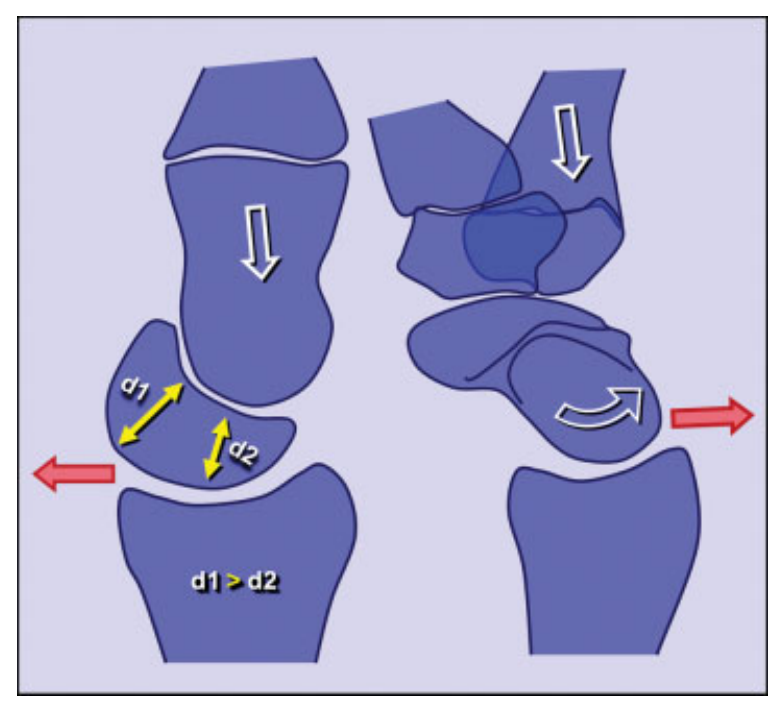

Fig. 3 The lunate tends to rotate into extension and translate palmarly (red arrow) under axial load (white arrow) because it is wider palmarly than dorsally. The scaphoid, by contrast, tends to collapse into flexion and dislocate dorsally (red arrow) owing to its obliquity relative to the axis of the forearm.

under axial load, the lunate would always rotate into extension while the scaphoid would go into flexion under the same type of load ( $\mathbf{F i g . ~ 3 ) . ~ B a s e d ~ o n ~ t h i s , ~ t h e y ~ h y p o t h e s i z e d ~ t h a t ~}$ there is a dynamic, self-stabilizing mechanism by which the two bones do not dislocate in differing directions thanks to the scapholunate interosseous ligament, an important structure consisting of three distinct components: palmar, proximal, and dorsal. If that linkage disappears, the carpus is likely to collapse, with the scaphoid falling into full flexion and pronation, while the lunate extends and supinates.

What I liked about that explanation was that it helped understand why scapholunate dissociations displace the way they do, but also that it provided a guide to how to solve carpal instabilities: you reconstruct the scapholunate connection, and the carpus will be able to carry on again. This was a straightforward concept, and I got hooked by its the simplicity. Unfortunately, the balm of believing that I knew the truth did not last long; that model could explain only scapholunate instabilities. The pathomechanics of most other carpal instability patterns remained unanswered. That meant more curves in my road ahead.

\section{The "Self-Stabilizing Spring" Theory}

In 1983, I bought and carefully read The Wrist by Julio Taleisnik, ${ }^{18}$ another important person in my life. Dr. Taleisnik had always defended a modification of Navarro's columnar theory, ${ }^{19}$ in which the central column of the carpus was controlled not only by the scaphoid on the lateral side but also by the triquetrum on the medial side. Both of them would be important stabilizers, and their mechanism of action would be more or less as follows: Under axial load, the obliquely oriented scaphoid is likely to rotate into flexion. The triquetrum, by contrast, is likely to be pulled into extension by the

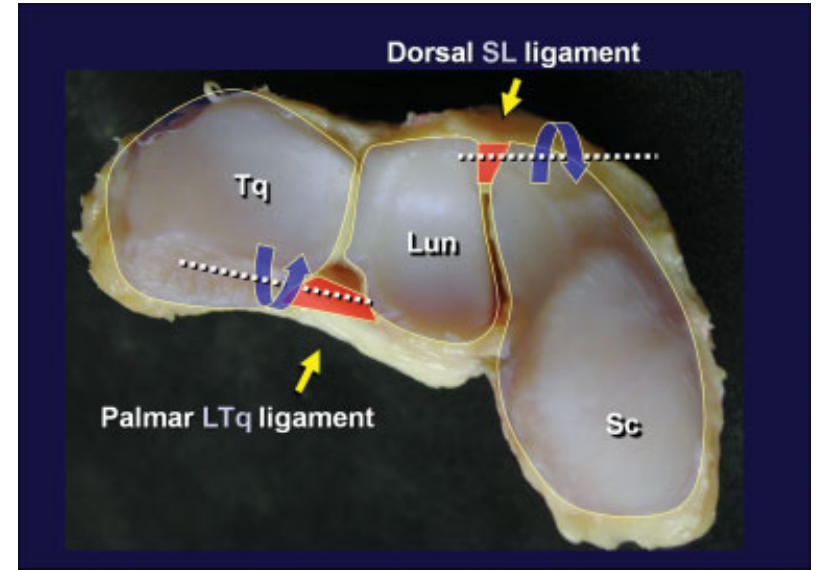

Fig. 4 Photograph of a disarticulated proximal carpal row seen from distal to proximal. The dorsal scapholunate ligament protects the scaphoid against excessive flexion, while the palmar lunotriquetral ligament controls extension of the triquetrum.

palmar hamatotriquetral ligament. Accordingly, if the ligaments connecting these bones are intact, the proximal row is likely to become dynamically stable. Based on these concepts, I proposed comparing the wrist to a spring with two prongs projecting in opposite directions (-Fig. 4). ${ }^{20}$ The more the spring is loaded from distal to proximal, the more stiff the spring becomes, and the greater the stability. To achieve equilibrium between these two opposite moments, all the ligaments in this system need to be intact, particularly the dorsal scapholunate ligament, which prevents scaphoid flexion, and the palmar lunotriquetral ligament, which prevents extension of the triquetrum. Not surprisingly, these are the thickest, the strongest, and biomechanically the most important of all proximal interosseous ligaments. ${ }^{21}$ I must confess that I was immediately seduced by the simplicity of this model. I looked at it from every perspective and could not find an objection against it. It was the model I had been looking for, so I started disseminating it in my lectures.

\section{The "Oval Ring Theory"}

It was about that time that I was offered the opportunity of working as visiting scientist at the Biomechanics laboratory of the Mayo Clinic in Rochester, Minnesota. That was, no doubt, the most rewarding time of my professional life, and I'll always be thankful to Drs. Green, Dobyns, and Chao for making it possible. Working with such great individuals such as Drs. An, Linscheid, Cooney, Amadio, Berger, Bishop, Horii, and Schuind was a big challenge, but also a beautiful experience. Once I got used to the Mayo Clinic ways of doing things, I proposed testing the "self-stabilizing spring" model of carpal stabilization in the cadaver. Tabloid journalists say, "Don't spoil a good story by sticking to the facts." That's exactly what happened when we tried to validate the "selfstabilizing spring" model in the laboratory: we spoiled our "good story." With the late Dr. Kobayashi, we used stereoradiographic techniques to verify whether it was true that the scaphoid flexes while the triquetrum extends when the 


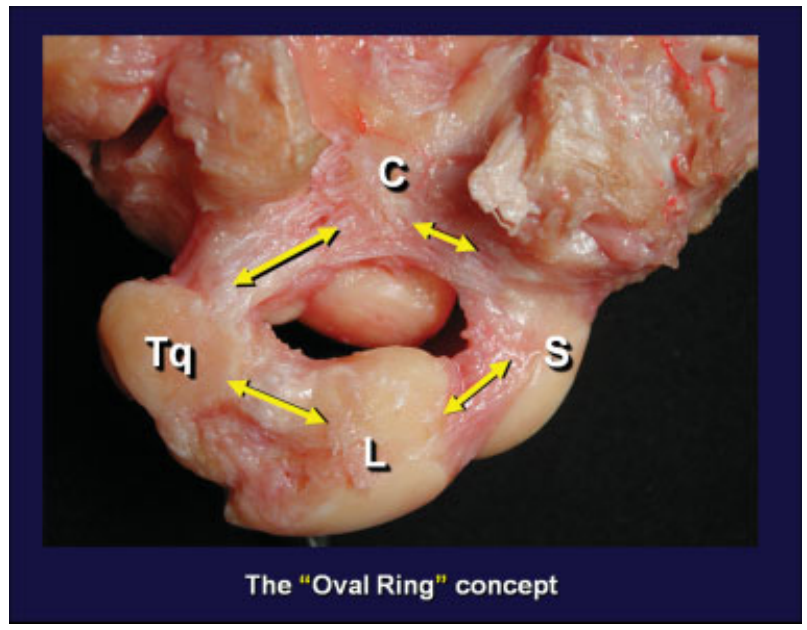

Fig. 5 Wrist dissection showing the four links (yellow arrows) that determine intracarpal stability, according to Lichtman's "oval ring model”23 C: capitate; S: scaphoid; L:Iunate; Tq: triquetrum.

neutrally positioned wrist is axially loaded. ${ }^{22}$ Much to my dismay, we found that what we had been teaching was not correct. We proved instead that, under axial compression, all three bones rotate into flexion. Indeed, when the wrist is axially loaded, the scaphoid flexion moment predominates over the triquetrum extension moment, and a "volar intercalated segmental instability" pattern of malalignment appears unless the two palmar midcarpal ligaments are intact: the one binding the capitate to the triquetrum and hamate, and the other linking the capitate to the scaphoid. Certainly, the more we looked into it, the more ligaments we found to be involved, and the more reasonable appeared the so-called oval ring concept suggested by David Lichtman $\left(\mathbf{- F i g . ~ 5 ) .} .^{23}\right.$ Yes, for the wrist to be stable there must be a mechanical interaction of joint compressive forces and the constraining effects of several ligaments in both the lateral and medial

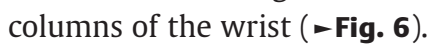

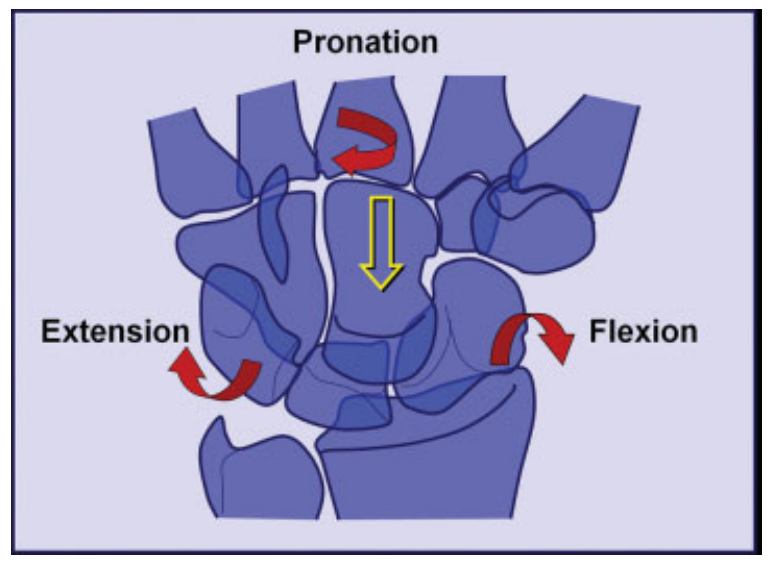

Fig. 6 Under axial load (yellow arrow), the distal row tends to rotate into pronation, the scaphoid into flexion, and the triquetrum toward extension (red curved arrows).

\section{Role of Wrist Proprioception in Carpal Stability}

There was one moment, however, when I started to feel uneasy working with simplified mechanical models, and I felt particularly uneasy thinking of ligaments as if they were like cables providing the only means of stability to the joint. No, ligaments could not be the only wrist stabilizers. If they were, how could gymnasts land on their wrists from considerable heights without suffering any injury at all? If the average yield strength of the dorsal scapholunate ligament is 260 newtons, ${ }^{21}$ which is $\sim 58$ pounds-force, how come it doesn't break more often? Of course, the answer had to be in the forearm muscles. By and large, the vast majority of mechanical models had ignored or underestimated the role of muscles in protecting these joints from injury. It was time for us to change that. It was time to study neuromuscular control of carpal stability.

First of all, we needed to know the mechanisms of wrist proprioception to clarify why and how our muscles know when they are required. Two research teams have been working on this: one led by Elisabet Hagert ${ }^{24,25}$ at the Karolinska Institute in Stockholm, Sweden, and the other by Richard Berger ${ }^{26}$ at the Mayo Clinic. The two teams had used sophisticated immunohistochemical analyses to identify, qualify, and quantify mechanoreceptors in the carpal ligaments. At that time, I was already in Spain, where in 1994, with my senior partner Alberto Lluch, we founded the Institut Kaplan, the first private hand center in the country. We envisioned a center emphasizing good-quality clinical practice, teaching, and research. The latter was mostly done at the Anatomy Department of the University of Barcelona, where we set up the URBES (Unitat de recerca de la biomecànica de l'extremitat superior) laboratory under the patronage of Professor Manuel Llusá.

In 2007, we established a collaboration with Elisabet Hagert, who was kind enough to spend time in our laboratory obtaining samples from the different wrist ligaments to evaluate the density and distribution of mechanoreceptors in the carpus. Interestingly enough, most ligaments inserted into the triquetrum were richly innervated with plenty of receptors, while other ligaments behaved like blind structures. ${ }^{25}$ Dr. Hagert's team had gone even further. Using ultrasound guidance, they inserted fine wire electrodes into the dorsal scapholunate ligaments of normal volunteers. ${ }^{24}$ After electrical stimulation of that ligament, the electromyographic activity in specific forearm muscles was recorded in different wrist positions. That investigation provided evidence of wrist ligamentomuscular reflexes, with early reactions being interpreted as a joint-protective function, while later co-contractions probably indicating supraspinal control of wrist stability (-Fig. 7). Of course, activity changes were not restricted to one muscle for each wrist position. Combined reactions were the rule. Unfortunately, we didn't have enough knowledge about the mechanisms by which muscles could influence carpal bone alignment. Certainly, there was a need for further research in this regard. That would be one of our main lines of research (-Fig. 8). 


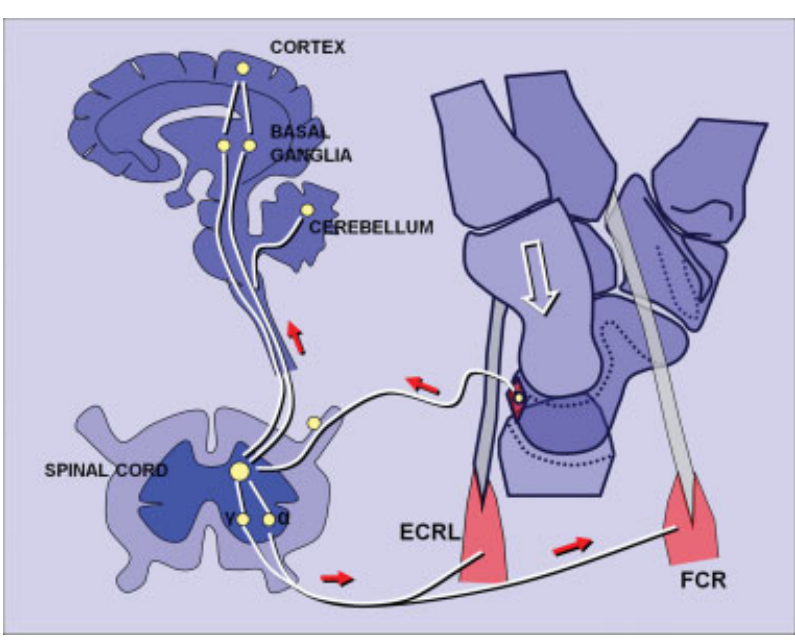

Fig. 7 Schematic representation of the ligamentomuscular reflexes that mediate proper neuromuscular wrist stabilization. Afferent and efferent stimuli (red arrows) communicate the stressed state of the ligament to the protective muscles.

\section{Role of Muscles in Carpal Stability}

In my lectures, I was used to saying that the most likely dynamic scaphoid stabilizer was the flexor carpi radialis (FCR). I had even worked on the hypothesis according to which, if an axial load was about to disrupt the dorsal scapholunate ligament, the mechanoreceptors contained in that ligament would detect such an unusual tension and would generate a warning message to the spinal cord, which would be followed by an almost automatic order to the FCR muscle, and a reactive contraction would correct the malalignment or, at least, prevent further ligament damage.

The concept of the FCR being a dynamic scaphoid stabilizer was not new. In fact, it was first published by Christian Jantea ${ }^{27}$

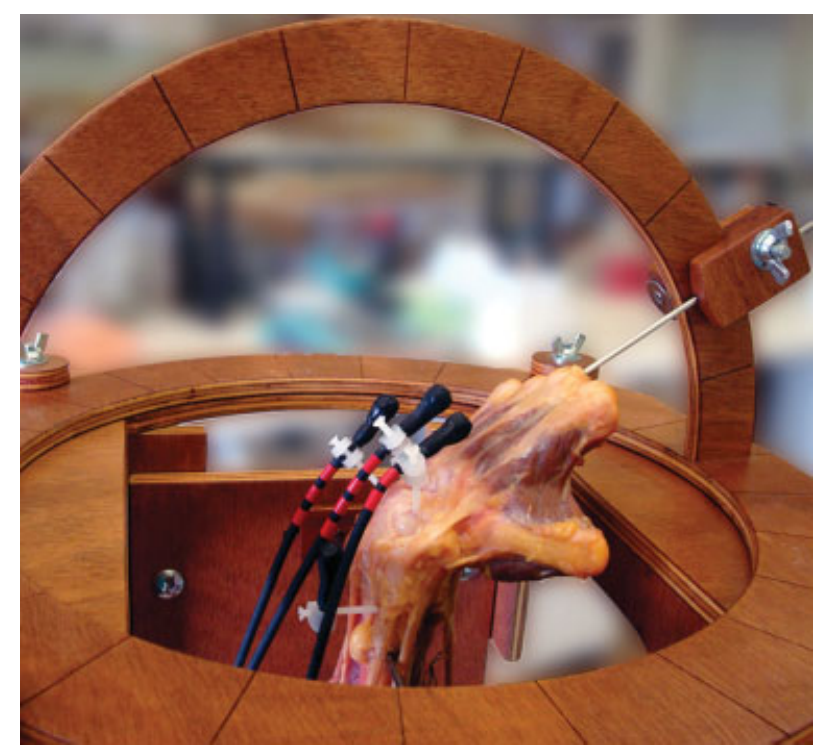

Fig. 8 Photograph of a specimen set in a specially designed jig to investigate the effect of individual muscle contraction in the alignment of the carpal bones. Black sensors are attached to specific bones to assess three dimensional carpal rotations. (URBES laboratory, Department of Anatomy, Universitat de Barcelona, Spain.) in 1994, based on the fact that the tendon uses the scaphoid as a pulley to increase its mechanical advantage. Moreover, because the FCR tendon angles around the scaphoid tuberosity, any contraction was likely to generate a dorsally directed vector that extends the scaphoid. It was such a nice explanation that I must admit that I felt a bit disappointed when it was not confirmed by Dr. Hagert's in vivo experiments. So we decided to do our own testing. With one of my doctoral fellows, Guillem Salvá, ${ }^{28,29}$ we completed a cadaver study in which we loaded the FCR tendon while holding the hand in neutral position. Scaphoid displacements were monitored using a highly accurate electromagnetic motion-tracking system. Once again, our hypothesis-according to which the FCR is able to induce extension to the scaphoidwas proved to be wrong. No matter how we placed the wrist, the scaphoid always flexed when axially loaded. Indeed, when forced against the scaphoid, the trapezium induces flexion, not extension as we had hypothesized. Obviously, we will have to find new explanations for these findings, and that is what we are doing right now in our laboratory.

\section{Summary}

Truly, my personal path toward understanding carpal kinetics has been characterized by a series of curves motivated by misconceptions that proved not to be good enough to explain reality. Indeed, there is no real advancement if one is not willing to reconsider one's ideas when new evidence suggests these not to be completely true.

In the beginning I thought that the wrist was an enigmatic articulation, with funny-shaped articular surfaces. Back then, the only bone that counted in providing stability was the scaphoid. Truly, that bone was regarded as the essential link between the two carpal rows. Then I learned about the importance of a precise interaction between the scaphoid, which tended to rotate into flexion, and the lunate, which tends to rotate into extension. And then I became convinced about the important stabilizing role of both the scapholunate and lunotriquetral ligaments in providing stability. The wrist was like a spring with two prongs directed in opposite directions. And then I realized that the proximal row, by itself, was not enough to guarantee stability to the wrist, and the oval ring concept came into place. But of course, when we studied the elastic properties of all carpal ligaments, it was obvious that they were not strong enough to be considered as cables holding bones in place. Stability could not depend only on ligaments. But then we learned about the existence of mechanoreceptors in those ligaments, and we had to admit that neuromuscular control had been by and large underestimated. And here we are now trying to unravel new evidence suggesting a complex system of ligamentomuscular reflexes. Indeed, for the wrist to be stable in kinetic terms, not only does joint geometry need to be intact, but also the ligaments must be mechanically and sensorily active to detect changes of tension to trigger specific muscle activations or inhibitions to control carpal rotation.

If carpal knowledge were a mountain, I must say that the hiking until now has been great. There have been times, however, when I thought that I was about to reach the top of 


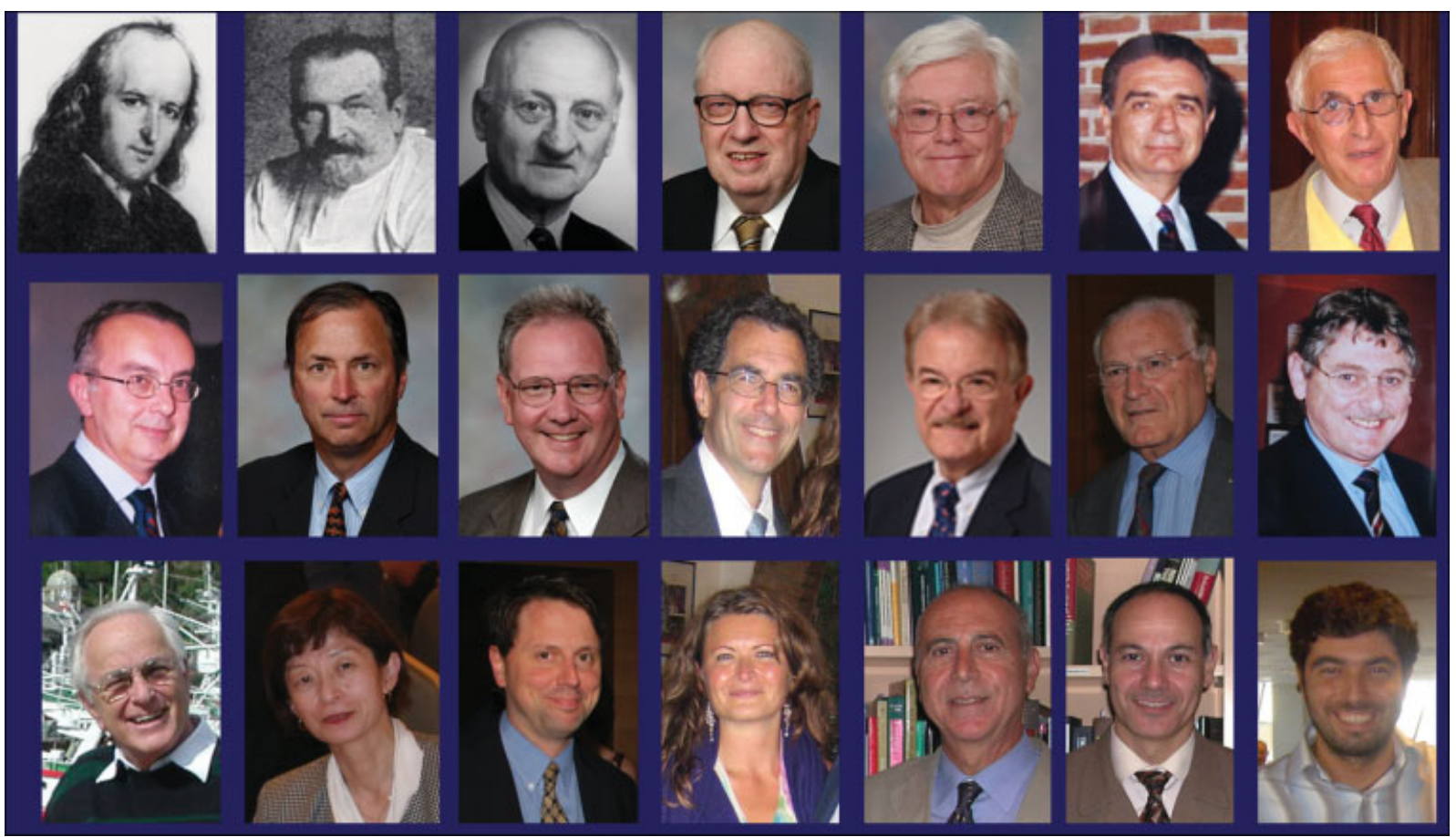

Fig. 9 Short list of those who inspired me to undertake-and those who came along on-such an exciting journey. From left to right, upper row: Drs Günther, Destot, Fisk, Dobyns, Linscheid, Taleisnik, Allieu. Middle row: Drs. Kauer, Cooney, Berger, Amadio, Lichtman, Saffar, Stanley. Lower row: Drs. Lanz, Horii, Heras-Palou, Hagert, Lluch, Ferreres, Lluch-Bergadá, and many more.

it. Of course, it looked as if the summit was right there....but it was not! I guess that, paraphrasing the ASSH past president Marybeth Ezaki, definitely, we are not there yet. But I'll never forget those who inspired me to undertake-and those who came along on-such an exciting journey (- Fig. 9). To all of them, and particularly to Ron Linscheid and Jim Dobyns, God bless you!

\section{Note}

*Adapted from the text of the International Guest Lecture delivered at the 63rd Meeting of the American Society for Surgery of the Hand, Chicago, Illinois, September 2008.

\section{Conflict of Interest None}

\section{References}

1 Linscheid RL, Dobyns JH, Beabout JW, Bryan RS. Traumatic instability of the wrist. Diagnosis, classification, and pathomechanics. J Bone Joint Surg Am 1972;54(8):1612-1632

2 Taleisnik J. Wrist: Anatomy, function, and injury. Instr Course Lect 1978;27:61-87

3 Dobyns JH, Linscheid RL. A short history of the wrist joint. Hand Clin 1997;13(1):1-12

4 Bell $\mathrm{Ch}$. The hand. Its mechanism and vital endowments as evincing design. London, England: William Pickering; 1833:84-85

5 Günther GB. Das Handgelenk in mechanischer, anatomischer und chirurgischer Beziehung. Hamburg, Germany: JA Meissner; 1841: $1-143$
6 Henke W. Die Bewegungen der Handwurzel. Zeitschrift für rationelle Medicin 1859;7:27-41

7 Henle J. Handbuch der Anatomie des Menschen, vol.1. Braunschweig, Germany: von Friedrich Vieweg and Sohn; 1871:153

8 Bryce TH. Certain points in the anatomy and mechanism of the wrist joint reviewed in the light of a series of Roentgen ray photographs of the living hand. J Anat Physiol 1896; 31(Pt 1):59-79

9 Corson ER. X-ray study of normal movements of the carpal bones and wrist. Proc Assoc Am Anat 1897;11:67-92

10 Fick R. Ergebnisse einer Untersuchung der Handbewegungen mit X-Strahlen. Anat Anz 1901;19(suppl):175-181

11 Destot É. The Classic: Injuries of the wrist: a radiological study. By Étienne Destot. 1926. Clin Orthop Relat Res 1986;202:3-11

12 Cooney WP III, Chao EYS. Biomechanical analysis of static forces in the thumb during hand function. J Bone Joint Surg Am 1977; 59(1):27-36

13 Fisk GR. Carpal instability and the fractured scaphoid. Ann R Coll Surg Engl 1970;46(2):63-76

14 Gilford WW, Bolton RH, Lambrinudi C. The mechanism of the wrist joint with special reference to fractures of the scaphoid. Guys Hosp Rep 1943;92:52-59

15 Allieu Y, Brahin B, Asencio G. Les instabilités du carpe. Bilan et sémiologie radiologique. Ann Radiol (Paris) 1982;25(4):275-287

16 Landsmeer JMF. Studies in the anatomy of articulation. I. The equilibrium of the "intercalated" bone. Acta Morphol Neerl Scand 1961;3:287-303

17 Kauer JMG. The interdependence of carpal articulation chains Acta Anat (Basel) 1974;88(4):481-501

18 Taleisnik J. The Wrist. New York, NY: Churchill Livingstone; 1985

19 Navarro A. Anatomy and physiology of the carpus [in Spanish]. In: Anales de Instituto de Clinica Quirúrgica y Cirugia Experimental. Montevideo, Uruguay: Imprenta Artistica de Dornaleche Hnos; 1935:166-189

20 Garcia-Elias M, Lluch A. Partial excision of scaphoid: is it ever indicated? Hand Clin 2001;17(4):687-695, x 
21 Berger RA, Imeada T, Berglund L, An KN. Constraint and material properties of the subregions of the scapholunate interosseous ligament. J Hand Surg Am 1999;24(5):953-962

22 Kobayashi M, Garcia-Elias M, Nagy L, et al. Axial loading induces rotation of the proximal carpal row bones around unique screw-displacement axes. J Biomech 1997;30(11-12): 1165-1167

23 Lichtman DM, Bruckner JD, Culp RW, Alexander CE. Palmar midcarpal instability: results of surgical reconstruction. J Hand Surg Am 1993;18(2):307-315

24 Hagert E, Persson JK, Werner M, Ljung BO. Evidence of wrist proprioceptive reflexes elicited after stimulation of the scapholunate interosseous ligament. J Hand Surg Am 2009;34(4):642-651

25 Hagert E, Garcia-Elias M, Forsgren S, Ljung BO. Immunohistochemical analysis of wrist ligament innervation in relation to their structural composition. J Hand Surg Am 2007;32(1):30-36
26 Lin YT, Berger RA, Berger EJ, et al. Nerve endings of the wrist joint: a preliminary report of the dorsal radiocarpal ligament. J Orthop Res 2006;24(6):1225-1230

27 Jantea CL, An KN, Linscheid RL, Coonney WP. The role of the sacpho-trapezial-trapezoidal ligament complex on scaphoid kinematics. In: Schuind F, An KN, Cooney WP III, Garcia-Elias M, eds. Advances in the Biomechanics of the Hand and Wrist. New York, NY: Plenum Press; 1994:345-361

28 Salvà-Coll G, Garcia-Elias M, Llusá-Pérez M, Rodríguez-Baeza A. The role of the flexor carpi radialis muscle in scapholunate instability. J Hand Surg Am 2011;36(1):31-36

29 Salva-Coll G, Garcia-Elias M, Leon-Lopez MT, Llusá-Perez M, Rodríguez-Baeza A. Effects of forearm muscles on carpal stability. J Hand Surg Eur Vol 2011;36(7):553-559 